\title{
O TABULEIRO DE DECIMAIS EM UMA CLASSE INCLUSIVA: UMA POSSIBILIDADE PARA ALUNOS COM DEFICIÊNCIA VISUAL*
}

\author{
MARCELO MARQUES DE ARAÚJO
}

\begin{abstract}
Resumo
O presente estudo teve como objetivo investigar quais as contribuições do Tabuleiro de Decimais quando utilizado no processo de ensino e aprendizagem das operações aditivas com os números decimais, visando a educação de uma aluna com deficiência visual no terceiro ciclo do Ensino Fundamental. A pesquisa foi desenvolvida na perspectiva qualitativa, tendo como participantes oito discentes de uma turma inclusiva do município de Belém (PA), sendo um destes alunos com deficiência visual. Foi utilizada como metodologia a pesquisa ação e a aplicação do Tabuleiro de Decimais, a fim de entendermos quais os são aspectos propositivos desta ferramenta para o ensino e aprendizagem da adição de números decimais, tendo como população alvo discentes com deficiência visual e sem deficiência. Os resultados obtidos pela pesquisa demonstraram que o uso do Tabuleiro de Decimais foi propositivo não só para o aprendizado e compreensão dos números decimais em operações aditivas com o discente com deficiência visual, bem como que para os demais alunos participantes sem deficiência visual.
\end{abstract}

\section{Introdução}

A educação é um processo interativo entre sujeito e objeto, além disso, é uma interação entre pessoas em desenvolvimento científico e social com o objetivo de possibilitar a cada indivíduo o pleno desenvolvimento de suas potencialidades, o preparo para o exercício da cidadania e sua qualificação para o mundo do trabalho (BRASIL, 1997).

Segundo Mantoan (2003), essa reflexão se encontra, atualmente, motivada internacionalmente por documentos e campanhas que visam demonstrar a importância da convivência com as diferenças. Tais iniciativas têm como referência a escola para todos, que representa uma diretriz dos organismos internacionais, reflete o desejo dos educadores críticos no sentido da universalização da educação.

*Palavras-chave: Metodologia de Ensino, Deficiência Visual, Números Decimais. †Doutor em Ciências e Matemática (UFMT); E-mail: marcelomarkes@uol.com.br 
A educação inclusiva surge como proposta de renovação da escola, na medida em que rejeita o ensino segregado. Sua origem esteve ligada aos movimentos civis da sociedade que, progressivamente, incorporaram discussões na área de educação especial. Quanto à educação tradicional, as críticas são dirigidas, sobretudo, às suas práticas segregadoras, advindas de um corpo teórico-conceitual que pressupõe uma série de métodos especiais, o que resulta em um sistema de ensino que trata indivíduos de modo distinto e separado, conforme suas potencialidades. Porém, devido à grande demanda de alunos com deficiência, a discussão sobre a educação inclusiva faz-se necessária. O debate sobre a proposta inclusivista na educação transcorreu durante a década de noventa do século passado no Brasil, e prossegue, como afirma Montes (2002), recorrente e controvertido.

Neste novo paradigma curricular de inclusão, a ênfase e a responsabilidade pela aprendizagem são deslocadas do aluno e dirigidas para os procedimentos de ensino. $\mathrm{Ou}$ seja, não é o aluno com deficiência que tem que se adaptar sua forma de aprender ao ritmo da aula, mas ao contrário, o ritmo e dinâmica da aula é que devem ser adaptados para permitir a participação e a aprendizagem de todos os alunos. As aulas têm que adquirir uma dinâmica aberta, possibilitando atividades diversificadas, que incentivem a participação e colaboração de todos. Na escola inclusiva, a cooperação e não a competição é o instrumento utilizado para incentivar a aprendizagem. Cada aluno deve receber as condições para conhecer o seu próprio processo de aprendizagem, suas características e necessidades. Ter conhecimento de seus limites e, como meta, a superação dos mesmos.

Nesse contexto da educação inclusiva, o nosso objeto de investigação consistiu em avaliar a potencialidade do Tabuleiro de Decimais para o ensino da operação aditiva empregando números decimais voltadas a alunos com deficiência visual e sem deficiência visual, em uma turma inclusiva em uma escola regular no município de Belém (PA).

\section{A Matemática e o ensino para educandos com deficiência visual}

A literatura especializada tem proposto amplos estudos e pesquisas sobre como a didática e a metodologia de ensino podem possibilitar um aprendizado mais significativo e eficiente à educação de pessoas com deficiência sensorial, dentre eles os discentes com deficiência visual. Isso também está contido nas discussões da transformação da metodologia tradicional da Matemática para alunos sem problemas na 
acuidade visual com a criação e aplicação de metodologias voltadas a temáticas específicas da Matemática no seu uso com o público de educação especial, em especial, com alunos com deficiência visual.

Os autores têm afirmado que os materiais que são usados em sala de aula refletem diretamente a concepção pedagógica que os docentes têm do entendimento de sua própria prática no exercício de transformar os conteúdos em componentes, que possam ser melhores veículos de aprendizagens aos discentes. Observa-se que quando o professor usa metodologias homogeneizadoras, ele tem uma concepção de ensino, que não trabalha e nem acolhe as diferenças e não as entende como constituidoras da própria identidade da natureza humana.

Magalhães et al. (2002, p. 26) diferenciam deficiência primária (o não ver - a deficiência sensorial em si) de deficiência secundária (as barreiras pedagógicas) e concordamos quando defendem que algumas vezes, o que faz nascer a desvantagem do aluno com deficiência na escola não é o não ouvir, o não ver, mas o fato de a escola não encontrar alternativas para adequar o processo de ensino-aprendizagem às peculiaridades destes alunos.

Ao procurarmos materiais didáticos disponíveis, percebemos, a escassez de material adaptado, fato já constatado por Caiado (2003, p. 57) A autora referida afirma que "existem poucas traduções de livros didáticos na linguagem Braille e os materiais didáticos são insuficientes”. Em virtude desse quadro, intui-se que o aluno com deficiência visual sente-se excluído da rede regular de ensino.

Baumel e Castro (2003, p. 97) afirmam que "materiais e recursos são condicionantes de uma relação pedagógica eficaz, de respostas à inclusão dos deficientes visuais e de todos os alunos no processo escolar".

Concordamos com Cerqueira e Ferreira (2000, p. 24), quando afirmam que em nenhuma outra forma de educação os recursos didáticos assumem tanta importância como na educação especial de pessoas deficientes visuais. A carência de materiais adequados pode conduzir a aprendizagem da criança deficiente visual a um mero verbalismo, desvinculado da realidade; a formação de conceitos depende do íntimo contato da criança com as coisas do mundo; bem como alguns recursos podem suprir lacunas na aquisição de informações pela criança deficiente visual.

Ochaita e Espinosa (2004, p.183) afirmam que a cegueira tem consequências sobre o desenvolvimento e a aprendizagem no ambiente escolar, "tornando-se necessário elaborar sistemas de ensino que transmitam, por vias alternativas, a 
informação que não pode ser obtida através dos olhos". Conforme Sá, Campos e Silva (2007, p. 21), as crianças cegas operam com dois tipos de conceitos: aqueles que têm significado real para elas a partir de suas experiências; aqueles que fazem referência a situações visuais, que embora sejam importantes meios de comunicação, podem não ser adequadamente compreendidos ou decodificados e ficam desprovidos de sentido.

Nesse caso, essas crianças podem utilizar palavras ou expressões descontextualizadas, sem nexo ou significado real, por não se basearem em experiências diretas e concretas. Esse fenômeno é denominado verbalismo e sua preponderância pode ter efeitos negativos em relação à aprendizagem e ao desenvolvimento.

Esses autores corroboram Cobo, Rodriguez e Bueno (2003) ao afirmarem a importância da diversidade das experiências e tarefas para a construção de conceitos pelos deficientes visuais. Segundo esses autores, tais pessoas necessitam de grande estruturação dos conceitos para poderem assimilá-los e propiciarem um desenvolvimento e aprendizagem posterior, ao contrário dos indivíduos sem problemas na acuidade visual, que verificam grande quantidade de conceitos de maneira espontânea, graças à visão.

Durante pesquisas exploratórias com alunos desprovidos de visão, Leite et al. (2010) perceberam como muitas vezes alguns assuntos não são abordados simplesmente por não saber como fazê-lo. O tratamento da informação é um conteúdo importantíssimo para todo aluno. Então, nada mais natural que todos tenham acesso a esse conhecimento dentro da escola. Por ter limitações, os alunos cegos precisam de materiais especialmente desenvolvidos para o ensino-aprendizagem desse conteúdo.

Fernandes e Healy (2008) falam acerca dos procedimentos para melhorar o ensino da Matemática para alunos com deficiência visual nas escolas inclusivas adotando recursos pedagógicos adaptados para garantir que os educandos com deficiência visual possam atingir os mesmos níveis de aprendizagem matemática de seus colegas sem deficiência visual.

$\mathrm{Na}$ perspectiva do ensino de Matemática para alunos com deficiência visual, algumas questões amplas poderiam ser apresentadas: Que tipo de atitude pode ser adotada, a fim de se adaptar ou mesmo construir uma prática educativa de Matemática, que contemple as necessidades educacionais dos alunos com deficiência visual? Que características devem ter as atividades de ensino, para que alunos com deficiência visual motivem-se para estudar conteúdos relacionados a esse campo do conhecimento? Em quais referenciais de ordem sensorial e educacional as citadas atividades devem ser 
estruturadas e conduzidas para que alunos com a referida deficiência motivem-se a aprender Matemática?

Evidentemente que as respostas a questionamentos como os acima colocados encontram-se principalmente no rompimento de hábitos estabelecidos em práticas educativas tradicionais e que se constituíram em modelos de como se deve dar aula. Quais atividades metodológicas devem ser usadas? Como se deve avaliar? (CAMARGO; SILVA, 2003). Nesse sentido, buscando contribuir com a construção de uma prática de ensino de Matemática que contemple especificidades sensoriais e educacionais de alunos com deficiência visual, desenvolveu-se um conjunto de atividades de ensino no âmbito do conceito inclusão, cuja estrutura fundamenta-se no desenvolvimento de ações de cunho institucional por parte da escola e da sociedade. Isto implica desde a preocupação de elaboração de metodologias e práticas metodológicas especiais para cada especificidade dos discentes até a valorização da diversidade humana no ambiente escolar. Com tais propósitos, não só o aluno com necessidades educacionais especiais tem o direito de aprender e desenvolver sua autonomia e sua escolarização na rede pública regular de ensino, mas todos os estudantes ali incluídos.

No campo de revisão para a área de pesquisa no que se refere ao desenvolvimento de teorias na área de Educação Matemática, esta pesquisa pretendia ampliar a discussão, visto a carência de pesquisas na área, no âmbito do ensino de números decimais para estudantes cegos em ambientes inclusivos.

\section{O ensino dos números decimais e seus desdobramentos}

O processo de ensino e aprendizagem da Matemática com a abordagem do conteúdo dos números decimais em aula aparece, geralmente, em nosso cotidiano, no sistema decimal ou no sistema de medidas, expressos pelo sistema monetário ou pelo sistema de medidas. Mas, ao estudá-los na escola, atribuímos aos mesmos significados diferentes dos encontrados no contexto diário. Os números decimais da forma que eram estudados na escola, abstratamente, não pareciam fazer sentido para o aluno que não consegue estabelecer relação entre o conhecimento escolar e a aplicabilidade desses números no dia-a-dia.

Essa descontextualização do ensino dos números decimais acarreta dificuldades no processo de ensino e aprendizagem. Isto porque, os alunos encontram dificuldades no momento em que são colocados em contato com os números com vírgulas. Zunino 
(1995, p. 29) deixa isso muito claro, ao afirmar que a "deficiência do aluno em operar com os números naturais só se manifesta em algumas situações, enquanto para os números decimais, o problema surge em várias situações nas quais eles aparecem envolvidos".

Diante das dificuldades que norteiam a problemática do ensino de números decimais, surgiu o interesse em realizar um estudo que ajudasse no processo de ensino e aprendizagem dos números decimais no contexto de alunos com deficiência visual inseridos no sistema regular de ensino. Vale ressaltar que minha vivência da prática docente, bem como na observação da prática de outros professores no ensino desse conteúdo, percebi que os alunos são levados a memorizar as regras das operações, que são esquecidas logo após as avaliações. Tal situação faz com que os estudantes sigam por séries posteriores sem saber operar com esses números. Isso talvez ocorra porque tendemos a reproduzir os modelos de ensino de nossos professores.

Parece que a forma como os números decimais vêm sendo tratados na escola não faz sentido para o aluno. Isso corrobora a quantidade de pesquisas que se tem desenvolvido em relação a esse conteúdo. Ao realizar a revisão da literatura especializada, percebemos as dificuldades que os alunos apresentam na compreensão do conceito/algoritmo dos números decimais, nos erros que cometem na leitura, representação e em operacionalizar esses números. Dos onze estudos analisados, encontramos apenas quatro que se propõem a apresentar propostas de ensino para amenizar as dificuldades sentidas pelos alunos.

\section{Justificativa da investigação}

Os motivos que nos fizeram optar por esta investigação e que a justifica são, dentre outros, os seguintes:

- O reduzido número de pesquisas sobre o processo de ensino e aprendizagem junto à educandos com deficiência visual em nosso contexto local, regional;

- A carência de se pensar em instrumentos de ensino a esse público no âmbito escolar;

- A grande dificuldade que esses discentes sentem no aprendizado dos números decimais, pois ainda indicam obstáculos epistemológicos e didáticos para a grande maioria dos discentes em nossa realidade;

- O ínfimo número de pesquisas e estudos existentes no nosso Estado acerca de se pensar e proporcionar elementos capazes de se operar na busca de qualidade na 
aprendizagem da Matemática, sobretudo, dos números decimais aos nossos educandos com necessidades educativas especiais, particularmente junto a discentes com deficiência visual;

- Provocar uma maior reflexão e problematização acerca do processo inclusivo em nosso contexto diante de barreiras ainda existentes e vivenciadas pelas pessoas com necessidades especiais em nosso contexto local e também regional.

\section{A pesquisa e o experimento usando o Tabuleiro de Decimais}

A presente investigação foi realizada em uma escola da rede pública da cidade de Belém (PA), que atendia uma aluna com deficiência visual no turno noturno e que tinha como identidade pedagógica ser designada como uma escola inclusiva.

Iniciamos com a aplicação de uma sondagem inicial com 20 questões aos discentes participantes, envolvendo atividades com os números decimais visando compreender qual entendimento os mesmos demonstravam obter sobre seu conceito e operações aditivas com o referido conteúdo. Na fase de intervenção da pesquisa, desenvolvemos cinco sessões com o uso da ferramenta metodológica proposta pelo nosso estudo - o Tabuleiro de Decimais. Após o entendimento e uso por parte dos discentes dessa ferramenta metodológica, desenvolvemos atividades com números decimais baseadas no sistema monetário e foram realizadas algumas atividades envolvendo a metodologia em questão com participação dos discente, respeitando o número de sessões, a fim de verificarmos se a metodologia contribuía e se demonstrava sensível para operar na aprendizagem e entendimento dos números decimais pelos referidos discentes.

No final desta intervenção, aplicamos uma sondagem de verificação contendo 20 questões, com os mesmos participantes, a fim de avaliarmos se houve algum êxito no entendimento dos mesmos após o período de intervenção junto aos discentes.

A metodologia Tabuleiro de Decimais representa uma ferramenta que usa a manipulação tátil para desenvolver cálculos, voltados a qualquer discente com ou sem deficiência, pois há uma representação dos números de 0 a 9 em cordas dispostas em duas fileiras, sendo que há 20 colunas no total, divididas nessas duas fileiras, 10 colunas na fileira superior e 10 colunas na fileira inferior, o que possibilita a escrita em frações e a escrita decimal também, com a possibilidade inclusive da inserção da vírgula, conforme indica a Figura 1. 
Figura 1: Representação da ferramenta Tabuleiro de Decimais

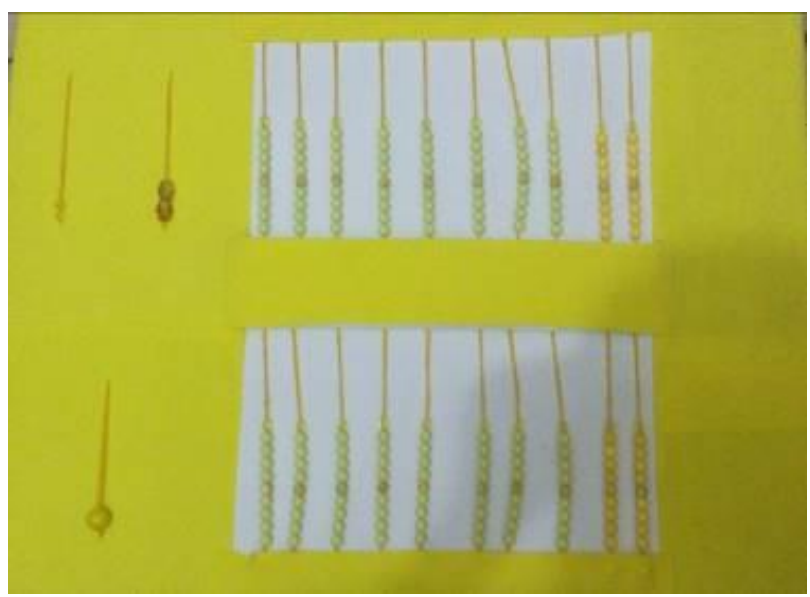

A representação do zero (0) constitui outra diferença do Tabuleiro, pois em todas as cordas, há uma conta com textura diferenciada na parte superior e inferior para marcar a escrita do zero. Ela, para os videntes, é a única que tem o tamanho menor e a cor transparente. Já os usuários com deficiência visual a identificam devido ao seu tamanho, por ser menor que as demais contas e, além disso, devido ao fato dessa conta especial apresentar uma viscosidade em toda sua forma que a diferencia das outras contas que indicam o número um (1) em diante. Há também outra diferença de textura e formato na conta usada para representar o número cinco (5), pois ela tem um formato mais quadrado, enquanto as demais são em formato arredondado. Assim, pelo toque, é fácil diferenciar a conta que representa o número cinco (5) das outras contas. A textura e o formato das contas que representam o zero (0) e o cinco (5) evitam que os discentes as confundam com as contas que representam os outros números. Mesmo que essa questão suscite grande debate na questão da escrita do zero, foi uma requisição dos próprios usuários com deficiência visual para diferenciar e facilitar algumas escritas no instrumento, tais como: 2 de 20, 20 de 200 e assim por diante.

O Tabuleiro de Decimais também apresenta uma ferramenta de comando no lado esquerdo que indica qual operação está sendo efetuada e, quanto ao uso de fração decimal, também há um comando para sinalizar tal procedimento, que é representado por o único comando arredondado na parte inferior do lado esquerdo do painel de comando, conforme percebido na Figura 1 acima. 
O Tabuleiro de Decimais também apresenta um acessório para facilitar o manuseio do instrumento, que pode ser acoplado entre as contas das colunas e cuja função é indicar a colocação da vírgula. $\mathrm{O}$ acessório pode ser detectado pelos usuários com deficiência visual por possui um formato triangular e, pelos videntes, por ser facilmente visualizado. Esse recurso possibilita a escrita em número decimal de modo mais simples e acessível e menos complexo que o manuseio do Soroban, conforme percebemos na representação do número 3,45, demonstrados na Figura 2.

Figura 2: Representação do número decimal 3,45 no Tabuleiro de Decimais

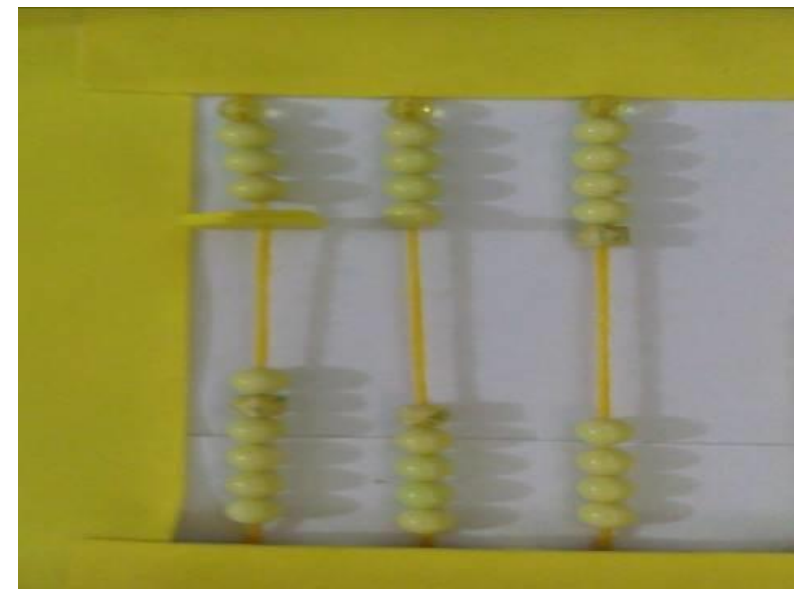

O instrumento foi inicialmente pensado e estruturado apenas como uma metodologia para ser usada para representar e transformar números decimais e posteriormente acabou tendo modificações para se efetuar operações de adição e subtração com os números naturais e decimais. A estrutura do Tabuleiro é de fácil manipulação e entendimento pelas crianças, sendo este o grande desafio e intuito da criação do referido instrumento. A intenção foi de criar algo que pudesse permitir a representação de frações decimais de forma simples e acessível para o pleno desenvolvimento de sua representação a essa clientela (alunos sem deficiência visual e com deficiência visual) em seu contato inicial com o assunto matemático e cobrir algumas lacunas que não haviam sido pensadas por outros instrumentos já existentes no processo de ensino e aprendizagem da Matemática.

Um primeiro desafio foi criar a possibilidade da escrita de fração de forma mais simples e em número decimal de modo que esta mesma escrita possibilitasse a inserção da vírgula de forma acessível e sem muita complexidade. Num primeiro momento, a 
experiência contou com a contribuição de diversos alunos com deficiência visual em estudos experimentais no processo de construção do recurso pedagógico, a fím de aperfeiçoar o instrumento nesta jornada. Inicialmente não havia pretensão de criar um novo instrumento didático. O Tabuleiro de Decimais nasceu da necessidade de ser um recurso pedagógico que pudesse possibilitar uma aprendizagem compartilhada entre os discentes com e sem deficiência visual, no intuito de construir uma ferramenta de partilha entre os referidos discentes. Uma forma de estarem mais parceiros e perceberem que juntos poderiam avançar e construir uma aprendizagem significativa e partilhada sem o estigma de que esse é um material apenas para alunos com deficiência.

Posteriormente, a metodologia usando o Tabuleiro de Decimais pode ser testada em uma turma inclusiva do terceiro ciclo do Ensino Fundamental, de uma escola no município de Belém (PA), turma esta composta de oito alunos, sendo um deles com deficiência visual.

Nossa ideia era trabalhar a subtração envolvendo os números decimais com o Tabuleiro de Decimais e ao mesmo tempo contemplar e exercitar a questão da adição relacionada ao mesmo procedimento, a fim de propor aos discentes um desafio ainda não exercitado nem em sala de aula ou no experimento. $\mathrm{O}$ intuito era tentar identificar como os mesmos iriam se comportar com duas atividades, as quais geralmente são realizadas de forma distintas nas aulas e exercícios de matemática, justapostas na mesma atividade, ou seja, os discentes iriam efetuar a subtração e adição na mesma atividade usando o referido instrumento de apoio, o que representa para Cunha (2002) um problema geralmente mais difícil de ser resolvido pelos discentes em sala de aula pela sua dinâmica de complexidade.

Optamos por trabalhar dentro de uma perspectiva que geralmente é pouco enfatizada no contexto escolar por entendermos que ela possa exemplificar um exercício mais complexo e ao mesmo tempo propiciador de reflexão e entendimento pelos discentes, a fim de possam abranger maiores possibilidades de interpretação visando a resoluções de problemas matemáticos de diversas formas e origens presentes no cotidiano. Essa possibilidade foi escolhida através da estratégia de inversão da sentença geralmente usada nos exercícios matemáticos realizados pelos discentes em sala de aula, tais como: $\mathbf{A}+?=\mathbf{C}$ ou $\boldsymbol{?}+\mathbf{B}=\mathbf{C}$, observando que o resultado $\mathbf{C}$ é o mesmo para as duas sentenças matemáticas. No caso da sentença $\mathbf{A}+?=\mathbf{C}$, o ponto de interrogação significa adicionar ao valor incial $\mathbf{A}$ um valor decimal correspondente à inflação. Para isso, usamos o jogo da inflação. Para a sentença matemática $?+\mathbf{B}=\mathbf{C}$, fizemos uma 
adaptação do jogo da inflação, de modo a utilizar o raciocínio inverso na próxima atividade que seria realizada pelos discentes; por isso, demos o nome ao novo jogo de jogo do desconto.

As atividades desenvolvidas sobre os números decimais foram questões baseadas em problemas práticos, que envolviam o sistema monetário, os quais foram indicados pelos próprios discentes através da aplicação da sondagem inicial junto aos mesmos. Elas se referiam aos alimentos que os discentes mais apreciavam consumir e seu respectivo valor que os discentes haviam atribuído. Foi desenvolvido, em conjunto com os discentes, dois jogos, um chamado de Jogo da inflação e outro Jogo do desconto para serem usados em atividades que envolvessem operações com adição e subtração, respectivamente, e jogados em dupla. O jogo consistia em os discentes tirarem duas cartas, sendo que a dupla tirava, no total duas cartas; isto é, cada participante da dupla tirava uma carta - duas cartas para a dupla. Cada carta continha dois itens, um item alimentar mais apreciado pelos participantes do experimento e o seu respectivo valor representativo, também indicado pelos próprios discentes, questão investigada na sondagem inicial aplicada.

O Jogo da inflação consistia em somar com uma nova carta que representava a inflação, ou seja, uma carta que representava um valor decimal, o qual seria adicionada às duas cartas tiradas anteriormente. Em outro momento, a carta com um valor decimal seria subtraída das duas cartas tiradas em outra etapa realizada pelos participantes, o que configurava o jogo do desconto.

A Figura 3 mostra os participantes fazendo atividades com o Tabuleiro de Decimais.

Figura 3: Uso da ferramenta Tabuleiro de Decimais pelos participantes

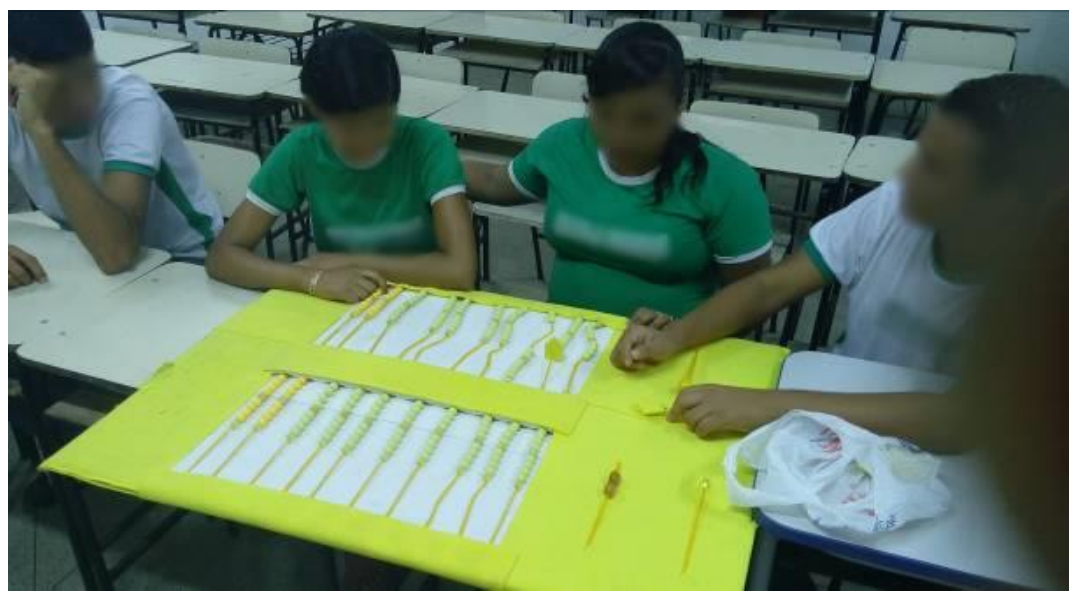


Esta atividade possibilitou um melhor entendimento do conceito e da operacionalização de atividades aditivas com os números decimais pelos discentes participantes da pesquisa e permitiu que houvesse trocas, interações e aprendizados entre os discentes sem deficiência visual e a discente com deficiência visual, fato que não era percebido naquele contexto educacional, além de construir pontes para novas possibilidades de valorização, entendimento e trocas afetivas para os discentes envolvidos nas atividades pedagógicas.

De acordo com Freitas (1999), os educandos precisam entender que uma relação de uso do conhecimento monetário resulta em uma operação matemática. O uso do conhecimento monetário constitui um elemento relevante não só para aprender matemática e números decimais, mas para fazer uso social e cultural do dinheiro de modo responsável e do pleno exercício de cidadania e entendimento do conceito de valor atribuído ao dinheiro em nosso contexto sociocultural.

Para Freitas (1999), estas experiências decorrentes do cotidiano do discente favorecem ao discente pensar matematicamente os conteúdos aprendidos em sua prática do dia a dia, por isso a escola deve saber usar este contexto monetário para o contexto curricular, visando favorecer ao discente um aprendizado atrelado ao uso social do conhecimento e dos conteúdos matemáticos de modo mais interligado de modo a fazêlo entender, refletir e usar tais situações a-didáticas em situações didáticas na construção deste entendimento e uso.

\section{Considerações finais e conclusão}

Ao propormos trabalhar a metodologia usada nesta pesquisa, tínhamos intenção de refletir junto aos pares que é possível todos aprenderem de uma forma diferente ao já estabelecido nas aulas de Matemática. Há diversas formas de propiciar a participação e aprendizagem de todos os educandos de forma mais interativa e colaborativa. Nossa intenção era mostrar que o discente, com alguma eventual deficiência sensorial, pode aprender e compartilhar junto com os demais alunos das mesmas potencialidades de aprender e se desenvolver. Ele não precisa ficar isolado ou ser trabalhado utilizando metodologias que o mantém segregado.

Concebemos que todos podem aprender e se desenvolver e que esta mediação pode ser conquistada de forma compartilhada e interativa entre todos, pois nestas interações muitos dogmas, preconceitos e intolerâncias serão superados e revistos por todos que possam fazer parte do processo. Cria-se a oportunidade de repensar e refletir 
sobre crenças e valores aprendidos que, muitas vezes, seguem a lógica excludente de convivência social.

Ao focarmos nossa investigação na aplicação de uma metodologia didática, não temos a intenção de concebermos que a educação inclusiva vai se efetivar e operar apenas neste viés, mas que a partir de novas formas e caminhos para se buscar e alcançar a aprendizagem e desenvolvimento dos educandos, vamos começar a pensar que a inclusão é de fato uma nova forma de conceber o processo de ensino e operar na busca de uma construção de cidadania na escola e pela escola.

A intenção dessa pesquisa foi provocar uma reflexão em todos os participantes envolvidos e em eventuais leitores, de que é possível mover a direção do olhar para o atendimento da diversidade humana. É possível movermos a aprendizagem usando outras possibilidades e caminhos do processo de ensino, o qual possa ser mais lúdico e ao mesmo tempo mais próximo do contexto social e cultural.

A atividade proposta também faz outra provocação ao sistema de ensino convencional. Fica evidente que podemos criar situações de ensino partindo do conhecimento trazido do educando, com atuação na zona de desenvolvimento proximal, para levá-lo ao conhecimento potencial, como preconiza a teoria sócio histórica de Vygotsky (1998). Enfatizamos que as atividades partiram do entendimento que os discentes tinham acerca do sistema monetário para aprenderem e moverem conhecimentos para a compreensão dos números decimais, por isso, podemos considerar que o objetivo de nossa pesquisa tenha sido cumprido, pois se constatou que as ações desenvolvidas foram claramente eficientes e facilitadoras para a compreensão dos números decimais, conforme foi verificado pelo aproveitamento do desempenho na etapa final de verificação da acomodação do conteúdo aplicado a todos os discentes participantes.

Os resultados demonstrados pela pesquisa inferem que o aluno com necessidade educativa especial tem capacidade de transpor barreiras e superar inúmeras dificuldades e limites impostos não pela presença de sua deficiência em si, mas pelo olhar dos outros em relação a mesma, pois este aluno demonstra, assim como os demais, disposição para superar suas eventuais dificuldades e anseia ocupar um lugar que lhe é de direito, através de seu mérito pessoal, basta que se crie as condições e se use as ferramentas geradoras de oportunidades para que isso seja possível.

$\mathrm{Na}$ perspectiva inclusiva, um eixo importante que precisa ser revisto e redimensionado é a formação inicial e continuada dos docentes, que possa atender aos 
pressupostos de um ensino inclusivo, proporcionando aos docentes competências e habilidades para identificar e atender as reais necessidades especiais de aprendizagem dos seus educandos, respeitando as suas limitações eventuais e valorizando suas potencialidades.

Assim, o maior desafio da educação brasileira é implementar uma educação que oportunize o desenvolvimento de todas as suas potencialidades; isso sim seria uma educação de fato inclusiva. Neste aspecto, a escola também precisa oportunizar um ambiente acolhedor e motivador para todos os seus sujeitos possam interagir e se desenvolver de forma livre, sem a presença de qualquer impedimento ou barreira de qualquer natureza, pedagógica ou arquitetônica, visando contemplar e atender a diversidade de todos e para todos em suas ações.

Esta pesquisa representa um trabalho inicial que pode ser ampliado com a discussão sobre o uso de instrumentos metodológicos, que possibilitem uma ação mais colaborativa e participativa entre os discentes dentro da perspectiva inclusiva. As sessões realizadas foram um passo na longa caminhada. Poderiam ser adotadas e experimentadas no sentido de oportunizar trocas mais colaborativas entre os educandos com ou sem deficiência sensorial. A metodologia do Tabuleiro de Decimais mostrou ser uma ferramenta pedagógica mais integrativa e dinâmica, por meio da qual todos juntos possam representar seus interesses e motivações na construção de um entendimento, reflexão, usos e ações mais conjuntas e interativas.

Neste sentido, a escolha metodológica contribui para uma reflexão a respeito das vantagens do ensino inclusivo, um ensino que não restringe, mas possibilita a ampliação do sistema educacional, de modo que todos os alunos, indistintamente, possam fazer uso ao mesmo tempo dos recursos didáticos disponíveis. Desta forma, os alunos passam a vivenciar (ou ver) o processo de aprendizagem sob uma outra perspectiva, passam a pensar numa inclusão, em um ensino que não restrinja, mas que possa dinamizar a ampliação da participação de todos. O aluno aprende, sob outra ótica, a ampliar as sensações e a estimular os seus sentidos para perceber não só a Matemática ou qualquer conteúdo dela provindo, mas aprende a aprender, aprende a pensar, aprende a ser, aprende a refletir na riqueza de informações e estímulos que são captados pelo nosso sistema sensorial.

Os resultados obtidos pela pesquisa indicaram que o uso do Tabuleiro de Decimais possibilitou um relevante aumento da compreensão nas operações aditivas com os números decimais pelos discentes (com ou sem deficiência visual), promoveu, 
também, um maior acolhimento, interação e socialização entre os discentes e contribuiu como uma ferramenta para diminuir o processo de segregação e incidir na conquista de caminhos voltados a sua valorização e inclusão.

\section{Referências}

BAUMEL, R. C. R. C; CASTRO, A. M. Materiais e recursos de ensino para deficientes visuais. In: RIBEIRO, M. L. S.; BAUMEL, R. C. R. C. Educação especial: Do querer ao fazer. São Paulo: Artmed, 2003.

BRASIL. Secretaria de Educação Fundamental. Secretaria de Educação Especial. Parâmetros Curriculares Nacionais: Adaptações Curriculares - Estratégias para a Educação de Alunos com Necessidades Educacionais Especiais. Brasília: MEC/ SEF/SEESP, 1997.

CAIADO, K. R. M. Aluno deficiente visual na escola: lembranças e depoimentos. Campinas, SP: Autores Associados; PUC Campinas, 2003.

CAMARGO, E. P.; SILVA, D. O Ensino de Matemática, Os alunos com deficiência visual e os Parâmetros Curriculares Nacionais: In: SIMPÓSIO EM FILOSOFIA E CIÊNCIA, V, 2003, Marília-SP. Anais eletrônicos: Atas Do V Simpósio Em Filosofia e Ciência, Trabalho e conhecimento: desafios e responsabilidades da ciência. Marília-SP, 2003.

COBO, A. D.; RODRÍGUEZ, M. G. ; BUENO, S. T. Personalidade e autoimagem do cego. In: MARTÍN, M. B.; BUENO, S. T. Deficiência visual: aspectos psicoevolutivos e educativos. São Paulo: Artmed, 2003.

CUNHA, M. R. K. A quebra da unidade e o número decimal: um estudo diagnóstico nas primeiras séries do Ensino Fundamental. 2001. 217f. Dissertação (Mestrado em Educação Matemática). Pontifícia Universidade Católica, São Paulo, 2002.

FERNANDES, S. H. A. A.; HEALY, L. Educação matemática e inclusão: abrindo janelas teóricas para aprendizagem de alunos cegos. Educação e Cultura Contemporânea, v. 5, n. 10, 2008.

FREITAS, R. Situações didáticas. In: MACHADO et al. Educação matemática: uma introdução. São Paulo: EDUC, 1999.

LEITE, H. C. A. et al. Gráficos e tabelas na ponta dos dedos: matemática para deficientes visuais. São Paulo: Contexto, 2010.

MAGALHÃES, R de C. P. et. al. Reflexões sobre a diferença: uma introdução à educação especial. Fortaleza: Demócrito Rocha, 2002.

MANTOAN, Maria Teresa Eglér (Org.). A integração de pessoas com deficiências: contribuições para uma reflexão sobre o tema. São Paulo: Mennon, 2003. 
MONTES, S. M. O aluno deficiente visual na escola: ponto vista do coordenador pedagógico, dos professores e dos alunos. Dissertação (Mestrado em Educação) - Faculdade de Filosofia, Ciências e Letras, Universidade Estadual Paulista, Marília. 2002.

OCHAÍTA, E.; ESPINOSA, M. A. Desenvolvimento e intervenção educativa nas crianças cegas ou deficientes visuais. In: COLL, C.; MARCHESI, A.; PALÁCIOS, J. (Org.). Desenvolvimento psicológico e educação. $2^{\text {a }}$. ed. Porto Alegre: Artmed, 2004.

SÁ, E. D. de.; CAMPOS, I. M. de; SILVA, M. B. C. Atendimento educacional especializado. Brasília/DF: SEESP/SEED/MEC, 2007.

VIGOTSKY, L. S. O desenvolvimento psicológico da infância. São Paulo: Martins Fontes, 1998.

ZUNINO, D. L. A matemática na escola: aqui e agora. $2^{a}$ ed. Porto Alegre: Artes Médicas, 1995. 